\title{
Effect of an Educational Intervention on Knowledge of Human Papillomavirus Vaccination among Pre-University Students in Malaysia
}

\author{
Ng Beng Kwang ${ }^{1 *}$, Tasneem Mahayudin ${ }^{2}$, Hii Ling Yien${ }^{1}$, Abdul Kadir Abdul \\ Karim $^{1}$, Chew Kah Teik ${ }^{1}$, Lim Pei Shan ${ }^{1}$
}

\begin{abstract}
Background: Cervical cancer is the fourth most common cancer among women worldwide. Studies evaluating the effect of health education on knowledge and perception of cervical cancer have generated conflicting results. Thus, this study aimed to evaluate the effect of educational intervention towards knowledge of HPV vaccination for cervical cancer prevention among pre-university students in Malaysia. Materials and Methods: This was an experimental before and after study performed between October 2014 and March 2015. Five hundred and eighty students were randomly assigned into intervention and control groups. All were required to complete both pre-intervention and post-intervention questionnaires. Those in the intervention group were given an information leaflet to read before answering the post-intervention questionnaire. Results: Almost half (48.3\%) of the students had poor knowledge, with a score less than 5, and only 51 (8.8\%) exhibited good knowledge, with a score of 11 and above. After educational intervention, the number of students with poor knowledge was reduced to $177(29.3 \%)$ and the number of students who exhibited good knowledge increased to 148 (25.5\%). Students from the intervention group demonstrated significant higher total scores in knowledge regarding 'HPV infection and cervical cancer' $(p=0.000)$ and 'HPV vaccination and cervical cancer prevention' $(p=0.000)$ during post-intervention as compared to the control group. Conclusions: Knowledge on HPV infection and vaccination is low among pre-university students. Educational intervention in the form of information leaflets appears effective in creating awareness and improving knowledge.
\end{abstract}

Keywords: Educational intervention - knowledge - HPV - vaccination - pre-university student - Malaysia

Asian Pac J Cancer Prev, 17 (1), 267-274

\section{Introduction}

Cervical cancer is the fourth most common cancer among women worldwide, with an estimated 528, 000 new cases and 266,000 deaths in 2012 (Ferlay et al., 2013). Developing and undeveloped countries accounted for $80 \%$ of cervical cancer occurrence, while $85 \%$ of deaths occured in developing countries (World Health Organization, 2007). It was the third most common female cancer in Malaysian after carcinoma of the breast and colorectal, where a total of 847 cases being diagnosed in the year 2007 (Malaysia Cancer Statistic, 2007).

High-risk Human Papilloma Virus (HPV) subtypes was found in almost all cervical cancers, $90 \%$ of anal cancers and up to $40 \%$ of external genitalia cancers including vulva, vagina and penile (Malaysia Cancer Statistic, 2007). Where as, low risk HPV subtypes were associated with genital warts (Baseman and Koutsky 2005). As for this, efforts had been made to provide primary prevention via HPV vaccination, preferably prior to the beginning of sexual activity, along with secondary prevention using Pap smear screening.

Despite significant magnitude of HPV infection, many studies demonstrated poor knowledge and awareness among their respondents (Dubai et al., 2010; Rashwan, Lubis and Ni, 2011; Reiter et al., 2011; Arrossi et al., 2012; McCusker et al., 2013; Darwish et al., 2014; Dodd et al., 2014; Wen et al., 2014). The success of vaccination is influenced by people's views, perception, understanding of HPV infection and the principles of vaccination. Studies that evaluated the effect of health education on knowledge and perception of cervical cancer showed conflicting results. Some studies managed to increase the knowledge, perception and awareness with subsequent increased in the uptake of cervical cancer screening (Choy, 2013; Abiodun et al., 2014; Cassidy et al., 2014) others showed no significant benefit of such educational interevention (Fu et al., 2014).

In Malaysia, Wong et al reported that the knowledge of HPV and HPV vaccination was low (Wong et al., 2009). The data regarding knowledge of HPV and HPV vaccination among pre-university students in 
Beng Kwang Ng et al

Malaysia was sparse. This research attempts to evaluate the knowledge of HPV and HPV vaccination among pre-university students as well as study the effect of educational intervention towards knowledge of HPV and HPV vaccination among them.

In Malaysia, a few studies were conducted to evaluate the knowledge and perception among young women and university students. However, similar studies conducted among pre-university students were limited. Previous research on the similar cohort of students showed poor level of knowledge (Kwang et al., 2014). Thus, an educational intervention was designed to improve their knowledge and ultimately increase the uptake of HPV vaccination to prevent cervical cancer.

\section{Materials and Methods}

\section{Research design}

This was an experimental-before and after study. It was conducted at a local institution that provides science matriculation program for 6 months duration form October 2014 to March 2015.

\section{Inclusion and exclusion criteria}

All students aged between 18 to 25 years old were recruited. They were local students who agreed to participate in the study. Foreign students and those who refused to participate were excluded.

\section{Research procedure}

Approval to conduct this study was obtained from the ethics committee of UKM Medical Centre. Permission to conduct the survey was given by the director of the preuniversity programme.

\section{Research instrument}

A set of questionnaire was used in this study. The questionnaire was based on an earlier study done on the similar cohort (Kwang et al., 2014). It was divided into three sections. Section A was the respondent's demographic data including gender, age, ethnicity, religion, educational level and marital status. Section B consists of 11 close-ended questions related to the knowledge of the respondents towards HPV and cervical cancer. Section $\mathrm{C}$ consists of 10 close-ended questions related to HPV vaccine. Correct responses in section $\mathrm{B}$ and section $\mathrm{C}$ were added up. Higher mark indicates better knowledge with score of 18 as the highest. The level of knowledge was divided into 3 categories according to the total scores i.e. poor (scores 0-5), moderate (scores 6-10) and good (scores 11-18).

Three hundred sealed envelopes were prepared for the intervention group and another three hundred sealed envelopes were prepared for the control group.

The envelopes for intervention group consist of:

i). Pre-interventional questionnaire; ii). Postintervention questionnaire; iii). A sealed envelope (in different colour) containing the information leaflet.

The envelopes for the control group consist of:

i). Pre-interventional questionnaire; ii). Postintervention questionnaire
** Pre-intervention questionnaire and post-intervention questionnaire contained same questions.

The students were randomly assigned into intervention group and control group. Effort was taken to make sure all the envelopes were well mixed. The sealed envelopes were distributed to the students when they entered the lecture hall. They were asked to open the envelope immediately. Those students who receive envelope for intervention group (extra small envelope with different colour) were asked to sit at left side of the lecture hall. Those received envelopes for control group were asked to sit at right side of the lecture hall. This was to ensure no discussion or sharing information leaflet between the two groups of students. A short briefing about the study was explained and informed consent was taken before they start answering the pre-interventional questionnaire.

All students were required to complete both the preintervention and post-intervention questionnaires. They were given 15 minutes to complete the pre-interventional questionnaire. The questionnaires were then collected. Subsequently, students in the intervention group were given another 15 minutes to read the information leaflet. Students in the control group were resting. At the final stage, all students were asked to answer the post-intervention questionnaire. The whole process took about 50-60 minutes. They were instructed to answer the questions solely in order to avoid being influenced by others.

The study was designed in such a way so that we are able to assess their knowledge about HPV and HPV vaccination via the pre-interventional questionnaire. To assess the extent of increment in students' knowledge after reading the information leaflet, we compared the scores obtained from the pre-interventional questionnaire to the scores obtained from post-interventional questionnaire for both intervention (received information leaflet) and control (no information leaflet) groups. We hypothesised that knowledge score in the intervention group would increase after educational intervention. To ensure that all students benefited from the study, the HPV information leaflets were distributed to all of them once they have finished answering post-intervention questionnaires.

The respondents' personal details and responses were kept confidential.

\section{Data analysis}

Data obtained were analyzed using SPSS version 21.0. Mean was used for normally distributed continuous variables and student T-test was used to compare mean score for the knowledge. Where as, paired T-test used to compare the mean scores before and after educational intervention.

Flow chart of study procedure (Figure Supplement 1)

\section{Results}

A total of 600 students were approached but only 580 students were recruited (response rate of $96.7 \%$ ). Sixteen students refused to participate as they were rushing for their class and four students were not interested without any specific reason. The baseline demographic 
Effect of Educational Intervention on Knowledge of HPV Vaccination among Pre-university Students in Malaysia

characteristics of the study subjects were shown in Table 1. The mean age was $18.0 \pm 0.20$ years old. Female students were greater in number than male students $(58.4 \%$ vs $41.6 \%$ ). Majority of them were Malays ( $94.7 \%$ ) followed by Others $(4.5 \%)$, Chinese $(0.7 \%)$ and Indian $(0.2 \%)$. Most of them were still single $(99.8 \%)$. Upon analysis, both control and intervention groups were well matched and there was no statistically significant difference between these two groups except age.

Pre-intervention knowledge for HPV infection and cervical cancer

The total scores for this section were 11. Before educational intervention, both control and intervention groups demonstrated poor knowledge with the mean score of $3.0 \pm 2.06$ and $2.9 \pm 2.33$ respectively. There were only $57.6 \%$ of the respondents aware that HPV could cause cervical cancer but more than half $(63.1 \%)$ of the respondents knew about the existence of vaccine to prevent HPV infection. Overall, there were only less than $30 \%$ of the respondents correctly answered the other questions in this section. Both control and intervention groups showed no statistically significant difference in terms of answers except in one particular question regarding "HPV can be passed from mother to her baby during birth"; in which respondents from intervention group fared better than the control group. Otherwise, there were no statistically significant differences in the total mean scores between the two groups $(\mathrm{p}=0.940)$. (Table 2$)$

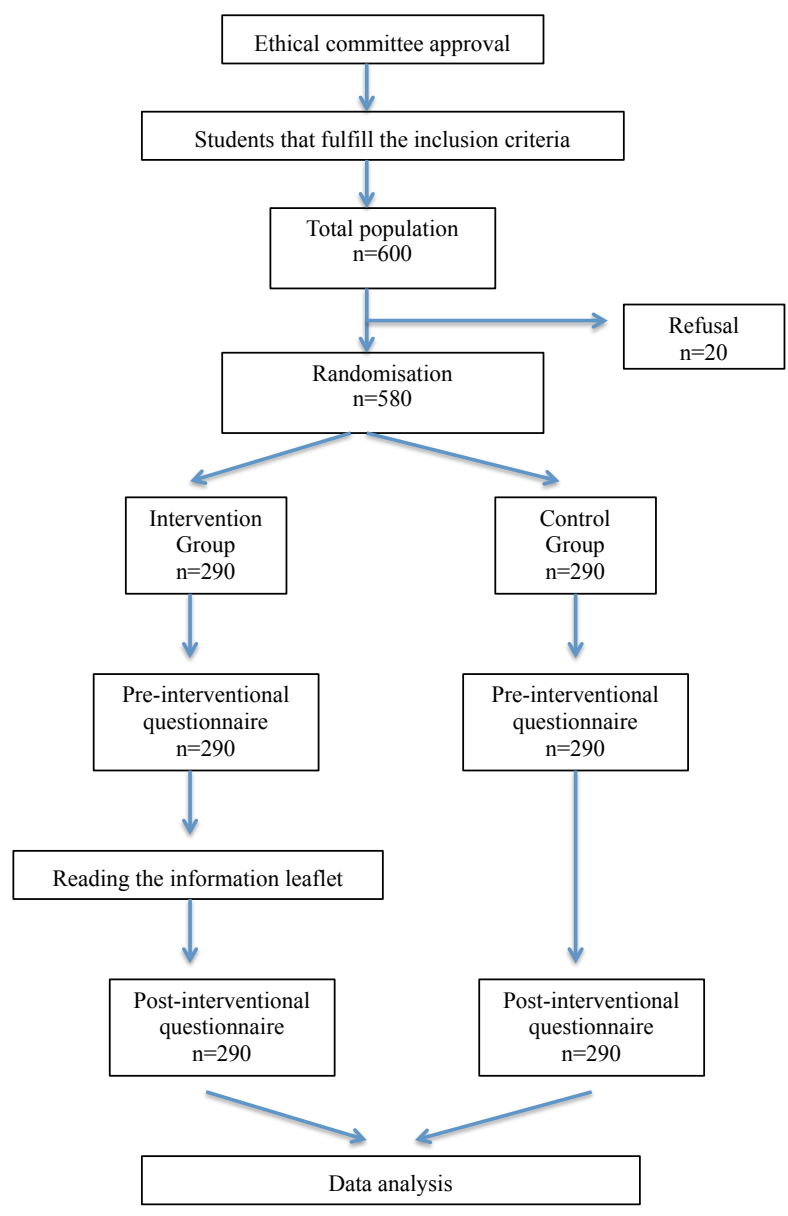

Figure Supplement 1. Flow Chart of Study Procedure
Pre-intervention knowledge for HPV vaccination and cervical cancer prevention

There were only $20.9 \%$ respondents aware that HPV vaccine could not protect against all types of virus strain that might cause cervical cancer and only $23.3 \%$ of the respondents aware that women who received HPV vaccine would still have to undergo Pap smear examination. There

Table 1.Demographic Characteristic of the Respondents

\begin{tabular}{|c|c|c|c|c|}
\hline & $\begin{array}{c}\text { Total } \\
(\mathrm{n}=580)\end{array}$ & $\begin{array}{l}\text { Control } \\
\text { group } \\
\mathrm{n}=290\end{array}$ & $\begin{array}{c}\text { Intervenion } \\
\text { group } \\
\mathrm{n}=290\end{array}$ & $\mathrm{p}$ \\
\hline Age (years) & $18.00 \pm 0.2$ & $18.00 \pm 0.3$ & $18.00 \pm 0.1$ & $\mathrm{p}=0.001$ \\
\hline \multicolumn{5}{|c|}{ Gender, n $(\%)$} \\
\hline Male & 241(41.6) & $125(43.1)$ & $116(40.0)$ & $X^{2}=2.170$ \\
\hline Female & $339(58.4)$ & $165(56.9)$ & $174(60.0)$ & $\mathrm{p}=0.448$ \\
\hline \multicolumn{5}{|c|}{ Ethnicity, n(\%) } \\
\hline Malay & $549(94.7)$ & $273(94.1)$ & $276(95.2)$ & $X^{2}=2.170$ \\
\hline Chinese & $4(0.7)$ & $3(1.0)$ & $1(0.3)$ & $\mathrm{p}=0538$ \\
\hline Indian & $1(0.2)$ & - & $1(0.3)$ & \\
\hline Others & $25(4.3)$ & $14(4.8)$ & $12(4.1)$ & \\
\hline \multicolumn{5}{|c|}{ Religion, $\mathrm{n}(\%)$} \\
\hline Islam & $552(95.2)$ & $276(95.2)$ & $276(95.2)$ & $\mathrm{X}^{2}=1.040$ \\
\hline Buddhist & $2(0.3)$ & $1(0.3)$ & $1(0.3)$ & $\mathrm{p}=0.792$ \\
\hline Hindu & $1(0.2)$ & - & $1(0.3)$ & \\
\hline Christian & $25(4.3)$ & $13(4.5)$ & $12(4.1)$ & \\
\hline \multicolumn{5}{|c|}{ Marital status, $\mathrm{n}(\%)$} \\
\hline Single & $579(99.8)$ & 289(99.7) & $290(100)$ & $X^{2}=1.002$ \\
\hline Married & $1(0.2)$ & $1(0.3)$ & - & $\mathrm{p}=0.317$ \\
\hline
\end{tabular}

*All parameter expressed in mean \pm SD unless specified

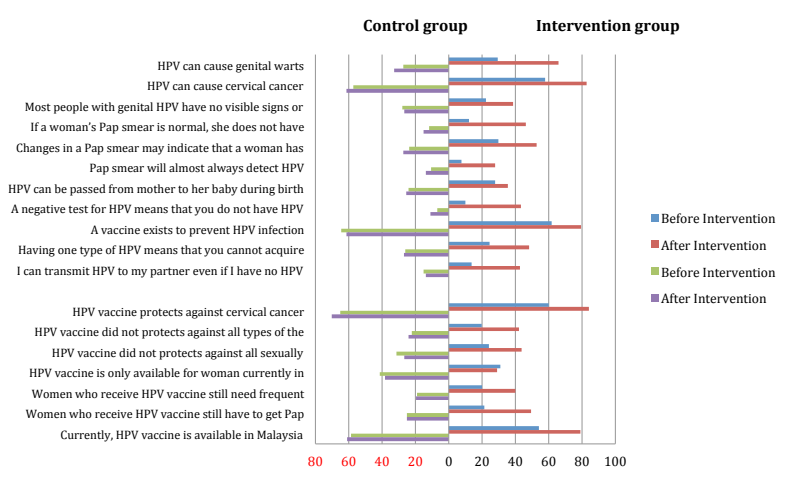

Figure 1.Students who had Correctly Answered Before and After Educational Intervention in Both Control and Intervention Group

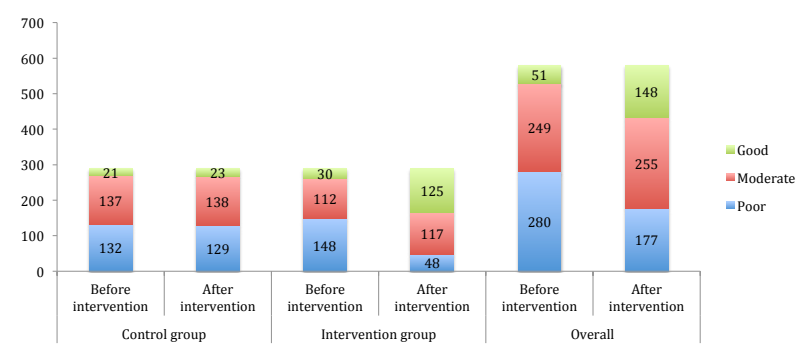

Figure 2. Overall Level of Knowledge before and after Educational Intervention 
Table 2. Students who had Correctly Answered and their Total Scores in Both Control and Intervention Group After Educational Intervention

\begin{tabular}{|c|c|c|c|c|}
\hline & Total & Control group & Intervenion group & م \\
\hline & $(\mathrm{n}=580)$ & $\mathrm{n}=290$ & $\mathrm{n}=290$ & p value \\
\hline \multicolumn{5}{|l|}{ HPV infection and cervical cancer } \\
\hline HPV can cause genital warts & $286(49.3)$ & $95(32.8)$ & $191(65.9)$ & $\mathrm{X}^{2}=71.037, \mathrm{p}=0.000$ \\
\hline HPV can cause cervical cancer & $418(72.1)$ & $178(61.4)$ & $240(82.8)$ & $\mathrm{X}^{2}=34.397, \mathrm{p}=0.000$ \\
\hline $\begin{array}{l}\text { Most people with genital HPV have no visible } \\
\text { signs or symptoms }\end{array}$ & $189(32.6)$ & $77(26.6)$ & $112(38.6)$ & $\mathrm{X}^{2}=19.119, \mathrm{p}=0.000$ \\
\hline $\begin{array}{l}\text { If a woman's Pap smear is normal, she does not } \\
\text { have HPV }\end{array}$ & $178(30.7)$ & $44(15.2)$ & $134(46.2)$ & $\mathrm{X}^{2}=68.237, \mathrm{p}=0.000$ \\
\hline $\begin{array}{l}\text { Changes in a Pap smear may indicate that a woman } \\
\text { has HPV }\end{array}$ & $232(40.0)$ & $79(27.2)$ & $153(52.8)$ & $\mathrm{X}^{2}=42.617, \mathrm{p}=0.000$ \\
\hline Pap smear will almost always detect HPV & $121(20.9)$ & $40(13.8)$ & $81(27.9)$ & $X^{2}=31.727, p=0.000$ \\
\hline $\begin{array}{l}\text { HPV can be passed from mother to her baby during } \\
\text { birth }\end{array}$ & $177(30.5)$ & $74(25.5)$ & $103(35.5)$ & $\mathrm{X}^{2}=6.862, \mathrm{p}=0.032$ \\
\hline $\begin{array}{l}\text { A negative test for HPV means that you do not } \\
\text { have HPV }\end{array}$ & $158(27.2)$ & $32(11.0)$ & $126(43.4)$ & $X^{2}=80.675, p=0.000$ \\
\hline A vaccine exists to prevent HPV infection & $408(70.3)$ & $178(61.4)$ & $230(79.3)$ & $\mathrm{X}^{2}=28.434, \mathrm{p}=0.000$ \\
\hline $\begin{array}{l}\text { Having one type of HPV means that you cannot } \\
\text { acquire new type }\end{array}$ & $218(37.6)$ & $78(26.9)$ & $140(48.3)$ & $\mathrm{X}^{2}=48.712, \mathrm{p}=0.000$ \\
\hline $\begin{array}{l}\text { I can transmit HPV to my partner even if I have no } \\
\text { HPV symptoms }\end{array}$ & $164(28.3)$ & $40(13.8)$ & $124(42.8)$ & $\mathrm{X}^{2}=60.248, \mathrm{p}=0.000$ \\
\hline Total scores, Mean $( \pm$ SD) & $4.4 \pm 2.78$ & $3.2 \pm 2.26$ & $5.6 \pm 2.70$ & $\mathrm{p}=0.000$ \\
\hline \multicolumn{5}{|l|}{ HPV vaccination and cervical cancer prevention } \\
\hline HPV vaccine protects against cervical cancer & $448(77.2)$ & $204(70.3)$ & $244(84.1)$ & $X^{2}=23.995, p=0.000$ \\
\hline $\begin{array}{l}\text { HPV vaccine did not protects against all types of } \\
\text { the virus strain that causes cervical cancer }\end{array}$ & $192(33.1)$ & $70(24.1)$ & $122(42.1)$ & $\mathrm{X}^{2}=32.173, \mathrm{p}=0.000$ \\
\hline $\begin{array}{l}\text { HPV vaccine did not protects against all sexually } \\
\text { transmitted infections }\end{array}$ & $204(35.2)$ & $77(26.6)$ & $127(43.8)$ & $\mathrm{X}^{2}=38.664, \mathrm{p}=0.000$ \\
\hline $\begin{array}{l}\text { HPV vaccine is only available for woman currently } \\
\text { in Malaysia }\end{array}$ & $195(33.6)$ & $111(38.3)$ & $84(29.0)$ & $X^{2}=67.112, p=0.000$ \\
\hline $\begin{array}{l}\text { Women who receive HPV vaccine still need } \\
\text { frequent pelvic examination }\end{array}$ & $173(29.8)$ & $57(19.7)$ & $116(40.0)$ & $\mathrm{X}^{2}=36.003, \mathrm{p}=0.000$ \\
\hline $\begin{array}{l}\text { Women who receive HPV vaccine still have to get } \\
\text { Pap smear }\end{array}$ & $216(37.2)$ & $73(25.2)$ & $143(49.3)$ & $\mathrm{X}^{2}=47.549, \mathrm{p}=0.000$ \\
\hline Currently, HPV vaccine is available in Malaysia & $406(70.0)$ & $177(61.0)$ & $229(79.0)$ & $\mathrm{X}^{2}=22.015, \mathrm{p}=0.000$ \\
\hline Total scores, Mean ( \pm SD) & $3.16 \pm 1.93$ & $2.7 \pm 1.77$ & $3.7 \pm 1.95$ & $\mathrm{p}=0.000$ \\
\hline $\begin{array}{l}\text { Overall score both 'HPV infection \& cervical } \\
\text { cancer' and 'HPV vaccination and cervical cancer } \\
\text { prevention', Mean }( \pm \text { SD) }\end{array}$ & $7.56 \pm 4.11$ & $5.8 \pm 3.49$ & $9.3 \pm 3.95$ & $\mathrm{p}=0.000$ \\
\hline
\end{tabular}

*All parameter expressed in mean \pm SD unless specified

were only $56.4 \%$ of the respondents knew that HPV vaccination was currently available in Malaysia despite the fact that it had been introduced in our country since 2010. The control group showed better understanding in the question regarding "HPV vaccine is only available for woman currently in Malaysia" as compared to intervention group ( $\mathrm{p}=0.032)$. Whereas, intervention group had more respondents who answered correctly in the question "Women who received HPV vaccine still need frequent pelvic examination" ( $p=0.013)$. Although the total mean scores for this section was higher in the control group as compared to the intervention group $(2.6 \pm 1.82$ vs $2.3 \pm 1.83$, $\mathrm{p}=0.033$ ), there was no statistical significant difference in the overall scores for sections regarding "HPV infection and cervical cancer" and "HPV vaccination and cervical cancer prevention" when the scores were totaled up $(5.6 \pm 3.46$ vs $5.5 \pm 3.69, \mathrm{p}=0.296)$. (Table 2)

\section{Total scores before and after educational intervention}

In intervention group, the total mean scores for "HPV infection and cervical cancer" and "HPV vaccination and cervical cancer prevention" showed statistically significant improvement after educational intervention $(\mathrm{p}=0.000)$. Thus, the overall score also increased statistically 
Table 2. Students who had Correctly Answered and their Scores in Both Control and Intervention Group Before Educational Intervention

\begin{tabular}{|c|c|c|c|c|}
\hline & Total & Control group & Intervenion group & \multirow{2}{*}{$\mathrm{p}$ value } \\
\hline & $(\mathrm{n}=580)$ & $\mathrm{n}=290$ & $\mathrm{n}=290$ & \\
\hline \multicolumn{5}{|l|}{ HPV infection and cervical cancer } \\
\hline HPV can cause genital warts & $164(28.3)$ & $79(27.2)$ & $85(29.3)$ & $X^{2}=1.685, p=0.431$ \\
\hline HPV can cause cervical cancer & $334(57.6)$ & $166(57.2)$ & $168(57.9)$ & $X^{2}=1.036, p=0.596$ \\
\hline $\begin{array}{l}\text { Most people with genital HPV have no visible signs } \\
\text { or symptoms }\end{array}$ & $146(25.2)$ & $81(27.9)$ & $65(22.4)$ & $\mathrm{X}^{2}=2.969, \mathrm{p}=0.227$ \\
\hline $\begin{array}{l}\text { If a woman's Pap smear is normal, she does not have } \\
\text { HPV }\end{array}$ & $69(11.9)$ & $34(11.7)$ & $35(12.1)$ & $\mathrm{X}^{2}=0.067, \mathrm{p}=0.967$ \\
\hline $\begin{array}{l}\text { Changes in a Pap smear may indicate that a woman } \\
\text { has HPV }\end{array}$ & $155(26.7)$ & $69(23.8)$ & $86(29.7)$ & $\mathrm{X}^{2}=2.966, \mathrm{p}=0.227$ \\
\hline Pap smear will almost always detect HPV & $53(9.1)$ & $31(10.7)$ & $22(7.6)$ & $\mathrm{X}^{2}=2.546, \mathrm{p}=0.280$ \\
\hline $\begin{array}{l}\text { HPV can be passed from mother to her baby during } \\
\text { birth }\end{array}$ & $151(26.0)$ & $70(24.1)$ & $81(27.9)$ & $\mathrm{X}^{2}=7.742, \mathrm{p}=0.021$ \\
\hline $\begin{array}{l}\text { A negative test for HPV means that you do not have } \\
\text { HPV }\end{array}$ & $49(8.4)$ & $20(6.9)$ & $29(10.0)$ & $\mathrm{X}^{2}=4.243, \mathrm{p}=0.120$ \\
\hline A vaccine exists to prevent HPV infection & $366(63.1)$ & $187(64.5)$ & $179(61.7)$ & $X^{2}=0.653, p=0.722$ \\
\hline $\begin{array}{l}\text { Having one type of HPV means that you cannot } \\
\text { acquire new type }\end{array}$ & $147(25.3)$ & $76(26.2)$ & $71(24.5)$ & $\mathrm{X}^{2}=0.232, \mathrm{p}=0.891$ \\
\hline $\begin{array}{l}\text { I can transmit HPV to my partner even if I have no } \\
\text { HPV symptoms }\end{array}$ & $84(14.5)$ & $44(15.2)$ & $40(13.8)$ & $\mathrm{X}^{2}=2.593, \mathrm{p}=0.273$ \\
\hline Total scores, Mean $( \pm \mathrm{SD})$ & $2.9 \pm 2.2$ & $3.0 \pm 2.06$ & $2.9 \pm 2.33$ & $\mathrm{p}=0.940$ \\
\hline \multicolumn{5}{|l|}{ HPV vaccination and cervical cancer prevention } \\
\hline HPV vaccine protects against cervical cancer & $363(62.6)$ & $189(65.2)$ & $174(60.0)$ & $\mathrm{X}^{2}=2.913, \mathrm{p}=0.233$ \\
\hline $\begin{array}{l}\text { HPV vaccine did not protects against all types of the } \\
\text { virus strain that causes cervical cancer }\end{array}$ & $121(20.9)$ & $64(22.1)$ & $57(19.7)$ & $\mathrm{X}^{2}=0.517, \mathrm{p}=0.772$ \\
\hline $\begin{array}{l}\text { HPV vaccine did not protects against all sexually } \\
\text { transmitted infections }\end{array}$ & $161(27.8)$ & $91(31.4)$ & $70(24.1)$ & $\mathrm{X}^{2}=4.795, \mathrm{p}=0.091$ \\
\hline $\begin{array}{l}\text { HPV vaccine is only available for woman currently } \\
\text { in Malaysia }\end{array}$ & $210(36.2)$ & $120(41.4)$ & $90(31.0)$ & $\mathrm{X}^{2}=6.890, \mathrm{p}=0.032$ \\
\hline $\begin{array}{l}\text { Women who receive HPV vaccine still need frequent } \\
\text { pelvic examination }\end{array}$ & $113(19.5)$ & $55(19.0)$ & $58(20.0)$ & $\mathrm{X}^{2}=8.740, \mathrm{p}=0.013$ \\
\hline $\begin{array}{l}\text { Women who receive HPV vaccine still have to get } \\
\text { Pap smear }\end{array}$ & $135(23.3)$ & $73(25.2)$ & $62(21.4)$ & $\mathrm{X}^{2}=1.870, \mathrm{p}=0.393$ \\
\hline Currently, HPV vaccine is available in Malaysia & $327(56.4)$ & $170(58.6)$ & $157(54.1)$ & $X^{2}=3.593, p=0.166$ \\
\hline Total scores, Mean $( \pm \mathrm{SD})$ & $2.4 \pm 1.83$ & $2.6 \pm 1.82$ & $2.3 \pm 1.83$ & $\mathrm{p}=0.033$ \\
\hline $\begin{array}{l}\text { Overall score both 'HPV infection \& cervical cancer' } \\
\text { and 'HPV vaccination and cervical cancer prevention', } \\
\text { Mean }( \pm \text { SD) }\end{array}$ & $5.4 \pm 3.58$ & $5.6 \pm 3.46$ & $5.5 \pm 3.69$ & $\mathrm{p}=0.296$ \\
\hline
\end{tabular}

*All parameter expressed in mean \pm SD unless specified

significant $(9.3 \pm 3.95$ vs $5.5 \pm 3.69, \mathrm{p}=0.000)$. (Table 3$)$

Further analysis in the control group showed total mean score for "HPV infection and cervical cancer" increased $0.2(\mathrm{p}<0.005)$. However, total mean scores for "HPV vaccination and cervical cancer prevention" remained low during post-intervention questionnaire. Hence, the overall mean score increased 0.2 as well $(\mathrm{p}<0.05)$. (Table 3)

When looking into each question before and after educational intervention, respondents in intervention group obviously did better in almost every question after educational intervention except "HPV is only available for woman currently in Malaysia”. (Figure 1) Not surprisingly the total mean scores for "HPV infection and cervical cancer", total mean scores for "HPV vaccination and cervical cancer prevention" and overall scores for both sections were significantly higher in the intervention group as compared to the control group following the educational intervention. (Table 4)

\section{Overall level of knowledge before and after educational intervention}

The overall level of knowledge before educational intervention was not satisfactory. There were 280 (48.3\%) 
Table 4. After Educational Intervention: Comparison of Scores between Control and Intervention Group

\begin{tabular}{lcccc}
\hline & Total & \multicolumn{2}{c}{ Control group } & Intervenion group \\
\cline { 2 - 4 } & $(\mathrm{n}=580)$ & $\mathrm{n}=290$ & $\mathrm{n}=290$ & \\
\hline Total score 'HPV infection and cervical cancer' & $4.4 \pm 2.78$ & $3.2 \pm 2.26$ & $5.6 \pm 2.70$ & $\mathrm{p}=0.000$ \\
Total score 'HPV vaccination and cervical cancer prevention' & $3.16 \pm 1.93$ & $2.7 \pm 1.77$ & $3.7 \pm 1.95$ & $\mathrm{p}=0.000$ \\
$\begin{array}{l}\text { Overall score ('HPV infection and cervical cancer' and 'HPV } \\
\text { vaccination and cervical cancer prevention' }\end{array}$ & $7.56 \pm 4.11$ & $5.8 \pm 3.49$ & $9.3 \pm 3.95$ & $\mathrm{p}=0.000$ \\
\hline
\end{tabular}

*All parameters expressed in mean $\pm \mathrm{SD}$

respondents exhibited poor knowledge, $249(42.9 \%)$ respondents had moderate knowledge and only $51(8.8 \%)$ respondents exhibited good knowledge. After educational intervention, the number of respondents who exhibited good knowledge had increased almost 3-fold to 148 $(25.5 \%)$ whereas the number of respondents with poor knowledge had reduced to 177 (30.5\%). This improvement in the level of knowledge was obvious in intervention group as compared to control group (Figure 2)

\section{Discussion}

This study demonstrated that the knowledge of our pre-university students on HPV infection, vaccination and cervical cancer prevention was poor. The total mean score before intervention was only 5.4 out of 18 (highest mark). This was consistent with earlier study done by Wong et al, revealed that knowledge on HPV among young women in a Southeast Asia country was extremely poor (Wong et al., 2009). Al-Dubai et al conducted another study with over 300 respondents from outpatient obstetrics and gynaecology clinic showing only $12-25 \%$ of their respondents answered correctly on questions about HPV and HPV vaccination (Al-Dubai et al., 2010). Where as, current study showed only $8.8 \%$ of the respondents displayed good knowledge before intervention.

Another large-scale survey over 1878 medical students in Southwest China showed that the knowledge of HPV were also poor; in which, only less than half of the students correctly answered over 10 out of 22 questions (Wen et al., 2014). This finding was not much different from the survey performed in developed countries such as USA, UK and Australia (Dodd et al., 2014).

Various barriers had been identified as the reason for poor acceptance of HPV vaccination and cervical cancer screening. Study by Vanderpool, Casey and Crosby showed that the important predictors for vaccine uptake were "vaccines are a good thing" and "I believed that getting the vaccine will be painful" (Vanderpool, Casey and Crosby 2011). On the other hand, the reasons for vaccine refusal including uncertainty about safety and efficacy; perception about receiving a sexually transmitted disease vaccination as well as perception of not being at risk of HPV infection (Wong 2011). A recent community-based intervention study in Japan identified few barriers for middle school girls to undergo cervical cancer screening including embarrassment, poor access and fear of having cancer (Ito et al., 2014).

Another study was conducted in USA to assess the knowledge of HPV vaccination among parents showed that the mean percentage of correct answers in a 20 -item knowledge test was only $36 \%$. Only $20.3 \%$ of them thought that "the government should mandate that children receive the vaccines' while $44.3 \%$ described that "school should not administer HPV vaccines to their students". This study shed some light on parents' issues as well as shortcomings in their knowledge. Hence, educational intervention might be able to improve the understanding and raise awareness among parents, thus influencing parental decisions regarding vaccination (Chang et al., 2013).

In our study, brief educational intervention in the form of information leaflet had effectively improved the respondents' knowledge on HPV. The total mean score of knowledge were higher among intervention group after reading the information leaflet as compared to control group $(9.3 \pm 3.95$ vs $5.8 \pm 3.49, \mathrm{p}=0.000)$. The percentage of correct answers to most of the questions also improved significantly. Hence, the overall number of respondents who exhibited good knowledge had increased nearly 3-fold from $51(8.8 \%)$ to $148(25.5 \%)$ after educational intervention.

Our findings were consistent with a multi-center survey in Mainland China, which revealed significant improvement in the knowledge on HPV, and cervical cancer as well as vaccine acceptability among respondents post education instruction. There was a recorded 2-fold increase in the number of women ( $44 \%$ to $81 \%$ ) who were willing to vaccinate their children post-intervention (Grabiel et al., 2013). Similar finding was reported by Foley et al in USA in which after educational intervention, respondents were more knowledgeable regarding HPV vaccination and reported greater willingness to vaccinate themselves and their children (Foley et al., 2014). In Korea, four sessions of cervical cancer prevention program were developed for immigrant women. Their perceived susceptibility score had improved significantly and thus enhancing their cancer prevention behaviour (Choy 2013). Cassidy et al described the use of brochure and electronic alert telephone reminders resulted in significant increase in HPV vaccine uptake and dose completion. The respondents in intervention group were 9.4 times and 22.5 times more likely to have HPV vaccine uptake and complete the treatment doses (Cassidy et al., 2014).

An effective education program is essential to increase the knowledge and thus promoting a more positive attitude towards acceptance of HPV vaccination especially in young adolescent girls. A tailored educational program 
on cervical cancer prevention in 953 secondary school girls had successfully demonstrated greater knowledge and more positive attitude after program implementation (Kwan et al., 2011). Despite various studies demonstrating positive outcome after educational intervention program, a systemic review by $\mathrm{Fu}$ et al failed to demonstrate any strong evidence to recommend educational intervention for widespread implementation. However, the authors had recommended the need for further studies to determine the effectiveness of culturally competent intervention in order to reach the diverse populations (Fu et al., 2014).

The strength of this study lied in the selection of study population based on pre-university students aged between around 18 years old. These students were the young adolescents that had missed the opportunity for our national HPV vaccination program. In addition to the high response rate $(96.77 \%)$, the use of information leaflet helped to address a choice that these students would have to make in real life. However, few limitations had been identified in this study. Firstly, this study did not assess the perceived willingness to be vaccinated before and after the educational intervention. Thus, another follow-up study is necessary to find out whether the improved HPV knowledge would eventually lead to an increase in HPV vaccination uptake. Besides that, the questionnaires were answered by the respondents without full supervision. Therefore, discussion among the students potentially occurred. Lastly, due to the convenience sampling method and recruitment only from a single institution, these results might not represent the whole population in Malaysia.

conclusion: This study showed that knowledge on HPV among our pre-university students was unsatisfactory despite a national HPV vaccination program in our country for several years. Educational intervention in the form of reading information leaflet had effectively increased the knowledge of our respondents.

\section{Acknowledgements}

The author wished to thank the students who had participated in this study. This study was granted approval from UKM Research Ethics Committee and was given the project code FF-2014-393 but it was not funded. There was no conflicts of interest.

\section{References}

Abiodun OA, Olu-Abiodun OO, Sotunsa JO, et al (2014). Impact of health education intervention on knowledge and perception of cervical cancer and cervical screening uptake among adult women in rural communities in Nigeria. BMC Public Health, 14, 814.

Al-Darwish AA, Al-Naim AF, Al-Mulhim KS, et al (2014). knowledge about cervical cancer early warning signs and symptoms, risk factors and vaccination among students at a medical school in Al-Ahsa, Kingdom of Saudi Arabia. Asian Pac J Cancer Prev, 15, 2529-32.

Al-Dubai SA, Alshagga MA, Al-Naggar RA, et al (2010). Knowledge, attitudes and barriers for human papilloma virus (HPV) vaccines among Malaysian women. Asian Pac J Cancer Prev, 11, 887-92.

Arrossi S, Maceira V, Paolino M, et al (2012). Acceptability and uptake of HPV vaccine in Argentina before its inclusion in the immunization program: a population-based survey. Vaccine, 30, 2467-74.

Baseman JG, Koutsky LA (2005). The epidemiology of human papillomavirus infections. J Clin Virol, 32, 16-24.

Cassidy B, Braxter B, Charron-Prochownik D, et al (2014). A quality improvement initiative to increase HPV vaccine rates using an educational and reminder strategy with parents of preteen girls. J Pediatr Health Care, 28, 155-64.

Chang IJ, Huang R, He W, et al (2013). Effects of an educational intervention on HPV knowledge and vaccine attitudes among urban employed women and female undergraduate students in China: a cross-sectional study. BMC Public Health, 13, 916.

Choi SY (2013). Development of an Educational Program to Prevent Cervical Cancer among Immigrants in Korea. Asian Pac J Cancer Prev, 14, 5345-9.

Dodd RH, McCaffery KJ, Marlow LA, et al (2014). Knowledge of human papillomavirus (HPV) testing in the USA, the UK and Australia: an international survey. Sex Transm Infect, 90, 201-7.

Ferlay J, Soerjomataram I, Ervik M, et al (2013). GLOBOCAN 2012 v1.0, Cancer Incidence and Mortality Worldwide: IARC Cancer Base No. 11

Foley OW, Birrer N, Rauh-Hain JA, et al (2015). Effect of educational intervention on cervical cancer prevention and screening in Hispanic women. J Community Health. [Epub ahead of print].

Fu LY, Bonhomme LA, Cooper SC, et al (2014). Educational interventions to increase HPV vaccination acceptance: a systematic review. Vaccine, 32, 1901-20.

Grabiel M, Reutzel TJ, Wang S, et al (2013). HPV and HPV vaccines: the knowledge levels, opinions, and behavior of parents. J Community Health, 38, 1015-21.

Ito T, Takenoshita R, Narumoto K, et al (2014). A communitybased intervention in middle schools to improve HPV vaccination and cervical cancer screening in Japan. Asia Pac Fam Med, 13, 13.

Kwan TT, Tam KF, Lee PW, et al (2011). The effect of schoolbased cervical cancer education on perceptions towards human papillomavirus vaccination among Hong Kong Chinese adolescent girls. Patient Educ Couns, 84, 118-22.

Kwang NB, Yee CM, Shan LP, et al (2014). Knowledge, perception and attitude towards Human Papilloma Virus among pre-university students in Malaysia. Asian Pac J Cancer Prev, 15, 9117-23.

Malaysia Cancer Statistics- Data and Figure (2007). The third report of national cancer registry. Ministry of Health Malaysia. [Online]

Mccusker SM, Macqueen I, Lough G, et al (2013). Gaps in detailed knowledge of human papillomavirus (HPV) and the HPV vaccine among medical students in Scotland. BMC Public Health, 13, 264.

Rashwan H, Lubis SH, Ni KA (2011). Knowledge of cervical cancer and acceptance of HPV vaccination among secondary school students in Sarawak, Malaysia. Asian Pac J Cancer Prev, 12, 1837-41.

Reiter PL, Stubbs B, Panozzo CA, et al (2011). HPV and HPV vaccine education intervention: effects on parents, healthcare staff, and school staff. Cancer Epidemiol Biomarkers Prev, 20, 2354-61.

Vanderpool RC, Casey BR, Crosby RA (2011). HPV-related risk perceptions and HPV vaccine uptake among a sample of young rural women. J Community Health, 36, 903-9.

Wen Yi, Pan XF, Zhao ZM, et al (2014). Knowledge of Human papilloalomavirus (HPV) infection, cervical cancer, and HPV vaccine and its correlates among medical students 
Beng Kwang Ng et al

in Southwest Chinal: a multicenter cross-sectional survey. Asian Pac J Cancer Prev, 15, 5773-9.

Wong LP, Wong YL, Low WY, et al (2009). Knowledge and awareness of cervical cancer and screening among Malaysian women who have never had a Pap smear: a qualitative study. Singapore Med J, 50, 49-53.

Wong LP (2011). Knowledge and attitudes about HPV infection, HPV vaccination, and cervical cancer among rural Southeast Asian women. Int J Behav Med, 18, 105-11.

World Health Organization (2007). Cervical cancer, human papillomavirus (HPV), and HPV vaccines - Key points for policy-makers and health professionals. 